\title{
Valor nutritivo da cana-de-açúcar hidrolisada com hidróxido de sódio ou óxido de cálcio
}

[Nutritional value of the hydrolyzed sugarcane with sodium hydroxide or calcium oxide]

\author{
L.S.O. Ribeiro ${ }^{1}$, A.J.V. Pires $^{2}$, B.D. Pinho ${ }^{1}$, G.G.P. Carvalho ${ }^{3}$, M.A.L. Freire ${ }^{4}$ \\ ${ }^{1}$ Aluno de graduação - UESB - Itapetinga, BA \\ ${ }^{2}$ DTRA-UESB, Pesquisador do CNPq, \\ ${ }^{3}$ Aluno de pós-graduação - DZO-UFV - Viçosa, MG \\ ${ }^{4}$ Engenheiro agrônomo autônomo
}

\begin{abstract}
RESUMO
Avaliaram-se o valor nutritivo e a temperatura de estabilidade aeróbia da cana-de-açúcar hidrolisada com hidróxido de sódio $(\mathrm{NaOH})$ ou óxido de cálcio $(\mathrm{CaO})$. Utilizou-se um esquema fatorial $2 \times 4$, com dois aditivos $(\mathrm{NaOH}$ e $\mathrm{CaO})$ e quatro doses $(0 ; 0,75 ; 1,5$ e $2,25 \%$, com base na matéria natural), em delineamento inteiramente ao acaso com quatro repetições. $\mathrm{O}$ material foi acrescido dos aditivos e armazenado por 24 horas em baldes plásticos com capacidade de 10L. Ambos os aditivos controlaram o aumento da temperatura da cana-de-açúcar, e o $\mathrm{NaOH}$ mostrou-se mais eficiente. Os teores de matéria seca e matéria mineral aumentaram linearmente, enquanto os constituintes da parede celular diminuíram com o aumento das doses dos aditivos. Tanto o $\mathrm{NaOH}$ quanto o $\mathrm{CaO}$ promoveram acréscimo nos valores de digestibilidade da matéria seca da cana-de-açúcar. $\mathrm{O} \mathrm{NaOH}$ e o $\mathrm{CaO}$ melhoram o valor nutritivo da cana-de-açúcar, e o $\mathrm{NaOH}$ é mais eficiente.
\end{abstract}

Palavras-chave: forragem, Saccharum officinarum, tratamento químico

\begin{abstract}
The nutritional value and the temperature of aerobic stability of the hydrolyzed sugarcane by sodium hydroxide $(\mathrm{NaOH})$ or calcium oxide $(\mathrm{CaO})$ were evaluated. The experiment was carried out in factorial arrangment $2 \times 4$, two additives $(\mathrm{NaOH}$ and $\mathrm{CaO}$ ) and four doses $(0 ; 0.75 ; 1.5$; and 2.25\%), in a completely randomized design with four repetitions per treatment. The material, after the addition of the additive, was stored per 24 hours in 10-L plastic pails. Both additives controlled the increase of temperature of sugarcane, but $\mathrm{NaOH}$ was more efficient. The dry matter and mineral matter contents lineally increased, while the cell wall contents decreased with the increase of the doses. Either NaOH or $\mathrm{CaO}$ promoted increment in values of sugarcane dry matter digestibility. $\mathrm{NaOH}$ and $\mathrm{CaO}$ improved the nutritional value of the sugarcane and $\mathrm{NaOH}$ was more efficient.
\end{abstract}

Keywords: roughage, Saccharum officinarum, forage, chemical treatment

\section{INTRODUÇÃO}

A cultura de cana-de-açúcar, uma das principais atividades econômicas no Brasil, compõe o mais antigo setor agroindustrial do País e ocupa posição de destaque na economia local. Essa importância está relacionada à múltipla utilização da cana-de-açúcar, que pode ser utilizada in natura, sob forma de forragem para a alimentação animal e matéria prima para a indústria (Barbosa et al., 2006).

Apesar do grande potencial de utilização da cana-de-açúcar na alimentação de ruminantes, o elevado teor de componentes fibrosos, associado à baixa digestibilidade dos nutrientes em algumas situações, tem condicionado a baixos índices de produtividade animal (Vilela, 2007).

Recebido em 20 de fevereiro de 2009

Aceito em 30 de setembro de 2009

E-mail: leosampaio-zoo@hotmail.com 
Portanto, a utilização de volumosos de baixo valor nutritivo na alimentação animal pode ser uma alternativa interessante para amenizar os efeitos da estacionalidade de produção de forragem. Assim, a utilização de substâncias químicas no tratamento de volumosos visando melhorar a digestibilidade e a disponibilidade dos nutrientes tem sido estudada em diversos trabalhos (Carvalho et al., 2006; Pires et al., 2006) para utilização eficiente desses aditivos no tratamento químico de volumosos. Sarmento et al. (1999), Gesualdi et al. (2001) e Torres et al. (2003) indicaram o tratamento químico por meio de álcalis como alternativa viável na melhoria da qualidade desses alimentos.

Entre os produtos químicos mais utilizados no tratamento químico de volumosos, constam os hidróxidos de sódio, de potássio, de cálcio e de amônio, a amônia anidra e a ureia (Reis et al., 1995), e, desses tratamentos, os que utilizam amônia anidra, ureia e hidróxido de sódio são os mais empregados (Souza et al., 2002).

$\mathrm{Na}$ literatura, há vários resultados de pesquisa comprovando a melhoria no valor nutritivo de volumosos por meio de tratamentos químicos (Cândido et al., 1999; Reis et al., 2001; Santos et al., 2004; Castro Neto et al., 2008). Ezequiel et al. (2005), em pesquisa sobre os efeitos da hidrólise alcalina na cana-de-açúcar tratada com 0,75\% de hidróxido de sódio (peso/peso) sobre a digestibilidade, o consumo e a taxa de passagem da cana-de-açúcar, relataram que os valores de digestibilidade mais elevados foram obtidos com as dietas com cana-de-açúcar hidrolisada, hidrolisada fenada e hidrolisada ensilada, em comparação à cana-de-açúcar in natura. Esses autores verificaram que, com o tratamento alcalino, a digestibilidade da matéria seca (MS) aumentou $36,8 \%$ na cana-de-açúcar hidrolisada e $26,0 \%$ na cana hidrolisada fenada e hidrolisada ensilada.

O objetivo desse trabalho foi avaliar o valor nutritivo e a temperatura de estabilidade aeróbia da cana-de-açúcar hidrolisada com hidróxido de sódio ou óxido de cálcio.

\section{MATERIAL E MÉTODOS}

O experimento foi realizado em esquema fatorial $2 \times 4$, com dois aditivos, hidróxido de sódio $(\mathrm{NaOH})$ e óxido de cálcio $(\mathrm{CaO})$, aplicados em quatro doses $0 ; 0,75 ; 1,5$ e 2,25\%. As doses dos aditivos foram aplicadas com base na matéria natural da cana-de-açúcar, em delineamento inteiramente ao acaso com quatro repetições.

A cana-de-açúcar utilizada no estudo foi colhida manualmente, com retirada das folhas secas, aos 13 meses de idade, com teor de $21^{\circ}$ brix, no Campo Agrostológico da Universidade Estadual do Sudoeste da Bahia. Depois de colhida, a cana foi desintegrada em ensiladeira estacionária regulada para picagem em partículas de $2 \mathrm{~cm}$ de comprimento e homogeneizada. Amostras de cana-de-açúcar fresca (2kg) foram acondicionadas em baldes de polietileno com capacidade de $10 \mathrm{~L}$ para o tratamento com $\mathrm{NaOH}$ e o $\mathrm{CaO}$. A composição química da cana-deaçúcar in natura é evidenciada na Tab. 1.

Tabela 1. Composição química da cana-deaçúcar utilizada no experimento

\begin{tabular}{lc}
\hline \multicolumn{1}{c}{ Componente } & $\begin{array}{c}\text { Composição } \\
(\%)\end{array}$ \\
\hline Matéria seca $^{\prime}$ & 26,5 \\
Proteína bruta $^{1}$ & 2,2 \\
Fibra em detergente neutro $^{1}$ & 58,1 \\
Fibra em detergente ácido $^{1}$ & 40,6 \\
Hemicelulose $^{1}$ & 17,5 \\
Celulose $^{1}$ & 34,5 \\
Lignina $^{1}$ & 6,1 \\
Meteria mineral $^{1}$ & 4,1 \\
Digestibilidade $^{1}$ & 57,9 \\
Grau brix & 21,0
\end{tabular}

${ }^{\mathrm{T}}$ Porcentagem da MS

As doses de $\mathrm{NaOH}$ e $\mathrm{CaO}$ foram aplicadas à cana-de-açúcar, com homogeneização constante dentro dos baldes de polietileno. Depois de homogeneizado, o material foi mantido armazenado nos baldes, que permaneceram abertos, em local coberto por 24 horas. Após o período de tratamento, amostras foram coletadas, devidamente identificadas, empacotadas em sacos plásticos e armazenadas em freezer para posteriores análises laboratoriais.

Para a realização das análises químicas, as amostras foram pré-secas em estufa de ventilação forçada a $65^{\circ} \mathrm{C}$, por 72 horas, e posteriormente 
trituradas em moinho tipo "Willey" com peneira de crivos de $1 \mathrm{~mm}$. Foram avaliados os teores matéria seca (MS), matéria mineral, proteína bruta, fibra em detergente neutro, fibra em detergente ácido, hemicelulose, celulose e lignina, utilizando-se o método sequencial, conforme descrito por Silva e Queiroz (2005). O grau brix foi determinado por meio de refratômetro manual.

A digestibilidade foi avaliada pelo método de incubação in situ, com as respectivas repetições, por um período de 48 horas, utilizando-se um novilho mestiço Holandês $\times$ Indubrasil, com $280 \mathrm{~kg}$ de peso corporal, castrado, devidamente identificado e canulado no rúmen.

As amostras utilizadas na incubação ruminal foram moídas em peneira com crivos de $1 \mathrm{~mm}$ e acondicionadas em sacos de tecido-não-tecido (TNT), de $5 \times 5 \mathrm{~cm}$ de dimensão, em quantidade de aproximadamente $0,5 \mathrm{~g}$ de MS/saco, buscando-se manter relação próxima de $20 \mathrm{mg}$ de $\mathrm{MS} / \mathrm{cm}^{2}$ de área superficial do saco. Após 48 horas de incubação ruminal, os sacos foram lavados manualmente em água corrente, secos em estufa de ventilação forçada a $65^{\circ} \mathrm{C}$, por 72 horas, e imediatamente pesados para determinação da digestibilidade da matéria seca (DISMS).
Os dados foram avaliados por meio de análises de variância e regressão, utilizando-se o programa SAEG (Ribeiro Júnior, 2001).

\section{RESULTADOS E DISCUSSÃO}

A temperatura de estabilidade aeróbia da canade-açúcar hidrolisada durante 24 horas oscilou de acordo com as doses de $\mathrm{NaOH}$ e $\mathrm{CaO}$ (Fig. 1). $\mathrm{Na}$ cana-de-açúcar sem aditivo, a estabilidade foi comprometida, pois, no tempo zero hora, a temperatura foi de $25,7^{\circ} \mathrm{C}$ e, após seis horas, elevou-se para $30,1^{\circ} \mathrm{C}$, com aumento de $17,1 \%$ na temperatura. As doses de 0,$75 ; 1,5$ e 2,25\% promoveram maior estabilidade na temperatura, independentemente do aditivo usado, em comparação ao tratamento controle. $\mathrm{O}$ aumento gradativo da temperatura da cana-de-açúcar observado na cana-de-açúcar sem aditivo indica a ocorrência de intensa fermentação, que eleva a temperatura de maneira gradativa até atingir o pico máximo e a posterior queda, quando se verifica tendência de estabilização com a temperatura ambiente. A estabilização na temperatura pode estar associada ao consumo de carboidratos solúveis pelas bactérias, o que acarreta redução do valor nutritivo da cana-deaçúcar.

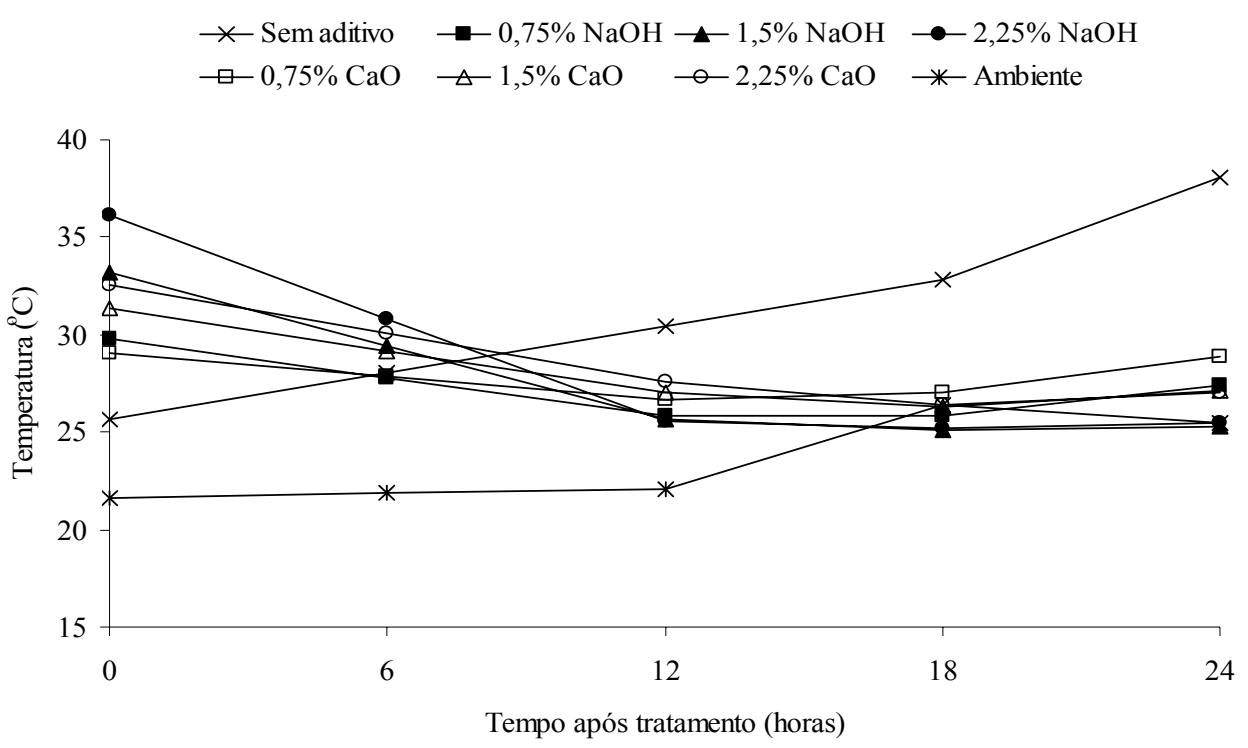

Figura 1. Temperatura de estabilidade aeróbia da cana-de-açúcar hidrolisada após adição de hidróxido de sódio $(\mathrm{NaOH})$ ou óxido de cálcio $(\mathrm{CaO})$, segundo o tempo após tratamento. 
Com a utilização dos aditivos $\mathrm{NaOH}$ e $\mathrm{CaO}$ na cana-de-açúcar, as temperaturas médias iniciais foram de 29,$8 ; 33,2$ e $36,1^{\circ} \mathrm{C}$ para a cana tratada com $\mathrm{NaOH}$ e de 29,$1 ; 31,4$ e $32,6^{\circ} \mathrm{C}$ para a tratada com $\mathrm{CaO}$ nas doses de 0,$75 ; 1,5$ e $2,25 \%$. Isso ocorre porque, no momento de mistura dos aditivos alcalinos, principalmente do $\mathrm{NaOH}$ com a cana-de-açúcar desintegrada, ocorre liberação de calor (reação exotérmica), a qual eleva a temperatura inicial. Contudo, com o aumento do período de tratamento (horas), ocorre redução na temperatura, que tende a estabilizar próximo à temperatura ambiente. Entretanto, maior temperatura durante o período foi observada no tratamento sem aditivo, com valores mínimos no tempo zero hora, $25,7^{\circ} \mathrm{C}$, e valores máximos após o tempo 24 horas, $38,4^{\circ} \mathrm{C}$, o que indica intenso processo fermentativo.

É possível inferir que o $\mathrm{NaOH}$ controlou o aumento de temperatura da cana-de-açúcar de forma mais eficaz que o $\mathrm{CaO}$, e que, a partir da dose de $0,75 \%$ de $\mathrm{NaOH}$, houve tendência de estabilização da temperatura durante todos os tempos estudados. Com o $\mathrm{CaO}$, isso só pôde ser observado a partir da dose de $1,5 \%$. Esses resultados provavelmente estão relacionados ao maior poder da reação de hidrólise do $\mathrm{NaOH}$ em relação ao $\mathrm{CaO}$.

Não foi observado efeito de interação $(\mathrm{P}>0,05)$ aditivos versus doses na hidrólise da cana-deaçúcar. O teor de MS aumentou de forma linear $(\mathrm{P}<0,05)$ de acordo com as doses de aditivos (Fig. 2). O teor médio de MS foi de $26,8 \%$ para a cana-de-açúcar sem aditivo e de 28,6 e $29,7 \%$ para a cana-de-açúcar hidrolisada com $2,25 \%$ de $\mathrm{NaOH}$ e $2,25 \%$ de $\mathrm{CaO}$, respectivamente, o que indica aumento de 6,7 e $10,8 \%$, que pode ser atribuído ao fato de os aditivos possuírem elevado teor de MS e também pelo fato de a cana-de-açúcar ter permanecido armazenada durante 24 horas em ambiente com temperatura variável (máxima de $26,4^{\circ} \mathrm{C}$ e mínima de $21,6^{\circ} \mathrm{C}$ ), o que ocasionou perda de umidade.

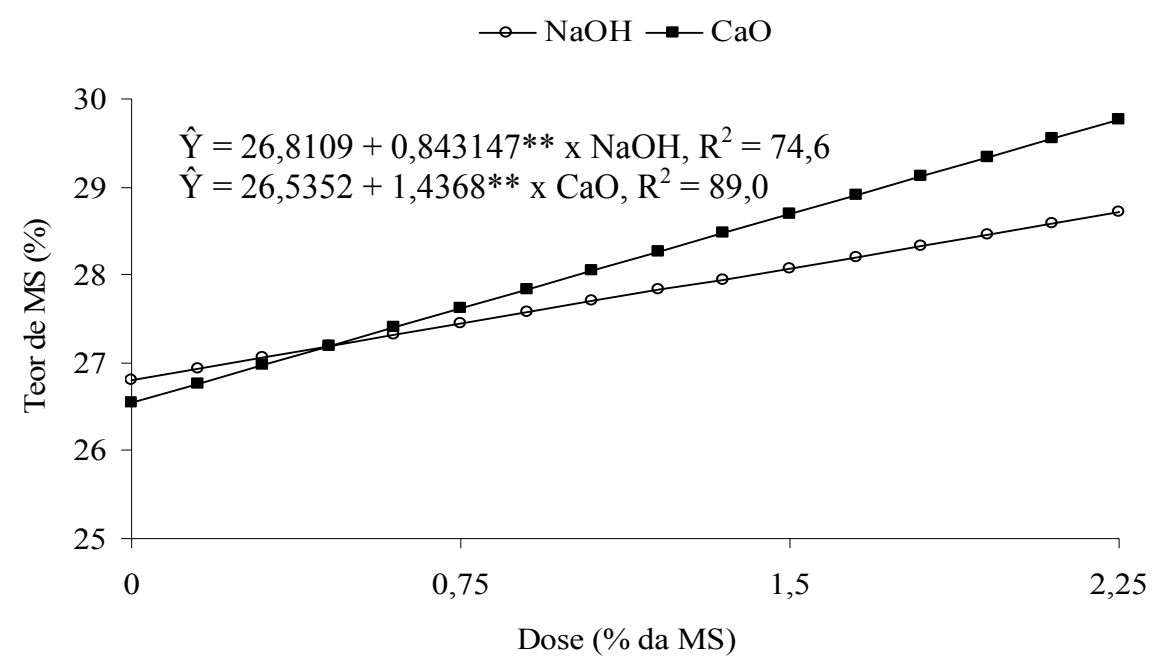

Figura 2. Teor de matéria seca (MS) da cana-de-açúcar tratada com diferentes doses de hidróxido de sódio $(\mathrm{NaOH})$ ou óxido de cálcio $(\mathrm{CaO})$. ${ }^{*} *$ Significativo a $1 \%$ de probabilidade.

Com base nas equações estimadas para aditivos (Fig. 2), verifica-se que, para o aumento de uma unidade de $\mathrm{NaOH}$ ou $\mathrm{CaO}$, houve, respectivamente, acréscimo de $0,84 \%$ e $1,43 \%$ de MS na cana-de-açúcar hidrolisada. Os resultados obtidos são semelhantes aos descritos por Cavali (2006), que trabalhou com silagem de cana-deaçúcar tratada com $\mathrm{CaO}(0,0 ; 0,5 ; 1,0 ; 1,5$ e $2,0 \%$ na matéria natural) e verificou que os teores de
MS das silagens aumentaram linearmente com o aumento das doses de $\mathrm{CaO}$.

Não houve efeito $(\mathrm{P}>0,05)$ de dose nem do aditivo sobre o teor de proteína bruta $(\mathrm{PB}) \mathrm{da}$ cana-de-açúcar, uma vez que o valor médio foi de $2 \%$ de $\mathrm{PB}$, independentemente das doses ou do tipo de aditivo. Esse resultado pode ser explicado pela ausência nesses aditivos de elementos que contribuam para o aumento do 
teor de $\mathrm{PB}$, diferentemente de outros aditivos químicos, como a ureia ou a amônia anidra, bastante utilizadas por possuírem poder de correção do teor de PB da cana-de-açúcar, por meio do aumento do nitrogênio não-proteico, como observado por Carvalho et al. (2006), em experimento com adição de ureia ao bagaço de cana-de-açúcar.

Para os constituintes da parede celular, não se observou efeito de interação $(\mathrm{P}>0,05)$ aditivos versus doses, no entanto houve efeito $(\mathrm{P}<0,05)$ das doses sobre os teores de fibra em detergente neutro (FDN) e fibra em detergente ácido (FDA), que apresentaram redução linear com o aumento das doses de $\mathrm{NaOH}$ e de $\mathrm{CaO}$. As reduções mais expressivas foram observadas com a dose máxima $(2,25 \%)$. O teor de FDN da cana-deaçúcar sem aditivo, de 59,2\% em média, reduziu para 46,4 e $47,9 \%$, respectivamente, na dose de 2,25\% de $\mathrm{NaOH}$ e $\mathrm{CaO}$ (Fig. 3). O teor médio de FDA foi de $41,4 \%$ para a cana-de-açúcar sem aditivo e de 34,3 e $33,5 \%$ para a cana-de-açúcar hidrolisada com $2,25 \%$ de $\mathrm{NaOH}$ e $\mathrm{CaO}$, respectivamente, o que indica redução de 17,1 e 19,1\% (Fig. 4).

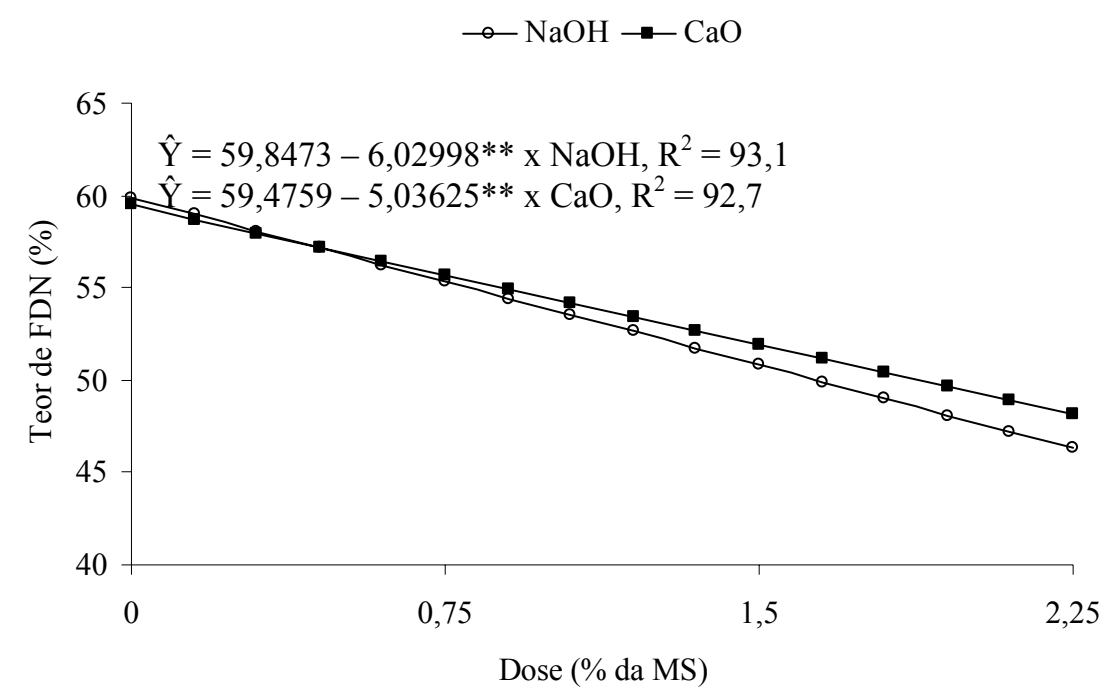

Figura 3. Teor de fibra em detergente neutro (FDN) da cana-de-açúcar tratada com diferentes doses de hidróxido de sódio $(\mathrm{NaOH})$ ou óxido de cálcio $(\mathrm{CaO})$. **Significativo a $1 \%$ de probabilidade.

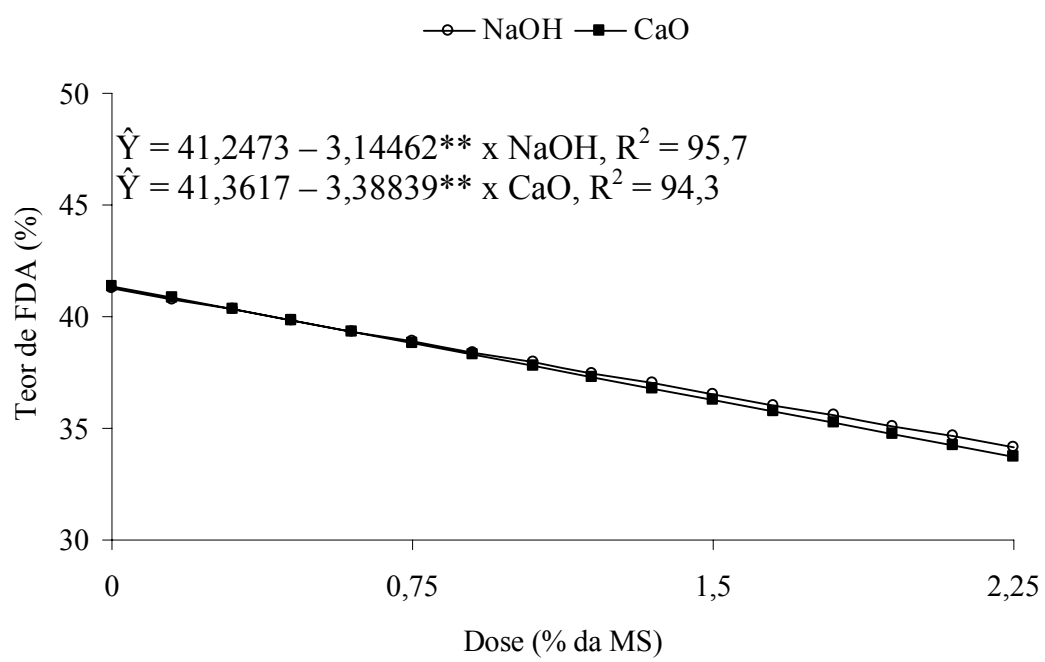

Figura 4. Teor de fibra em detergente ácido (FDA) da cana-de-açúcar tratada com diferentes doses de hidróxido de sódio $(\mathrm{NaOH})$ ou óxido de cálcio $(\mathrm{CaO}) .{ }^{*}$ Significativo a $1 \%$ de probabilidade. 
As doses de $\mathrm{NaOH}$ e $\mathrm{CaO}$ influenciaram $(\mathrm{P}<0,05)$ os teores de hemicelulose (Fig. 5) e celulose (Fig. 6), que apresentaram redução linear conforme aumentaram as doses. $\mathrm{O}$ teor médio de hemicelulose foi de $17,9 \%$ para a cana- de-açúcar sem aditivo e de 12,0 e 14,4\% para a cana-de-açúcar hidrolisada com $2,25 \%$ de $\mathrm{NaOH}$ e $\mathrm{CaO}$, respectivamente. Com essa dose (2,25\%), foram observadas reduções mais expressivas, com decréscimo de 33,0 e 19,6\%.

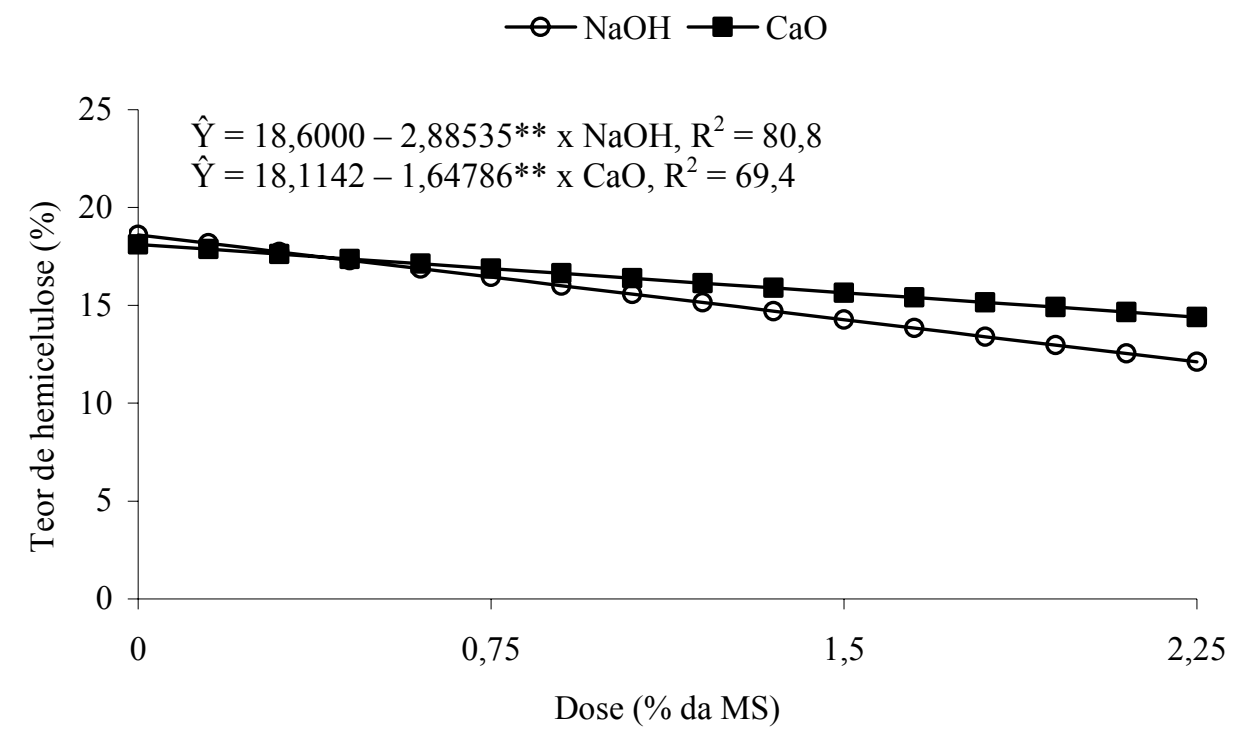

Figura 5. Teor de hemicelulose da cana-de-açúcar tratada com diferentes doses de hidróxido de sódio $(\mathrm{NaOH})$ ou óxido de cálcio $(\mathrm{CaO})$. **Significativo a $1 \%$ de probabilidade.

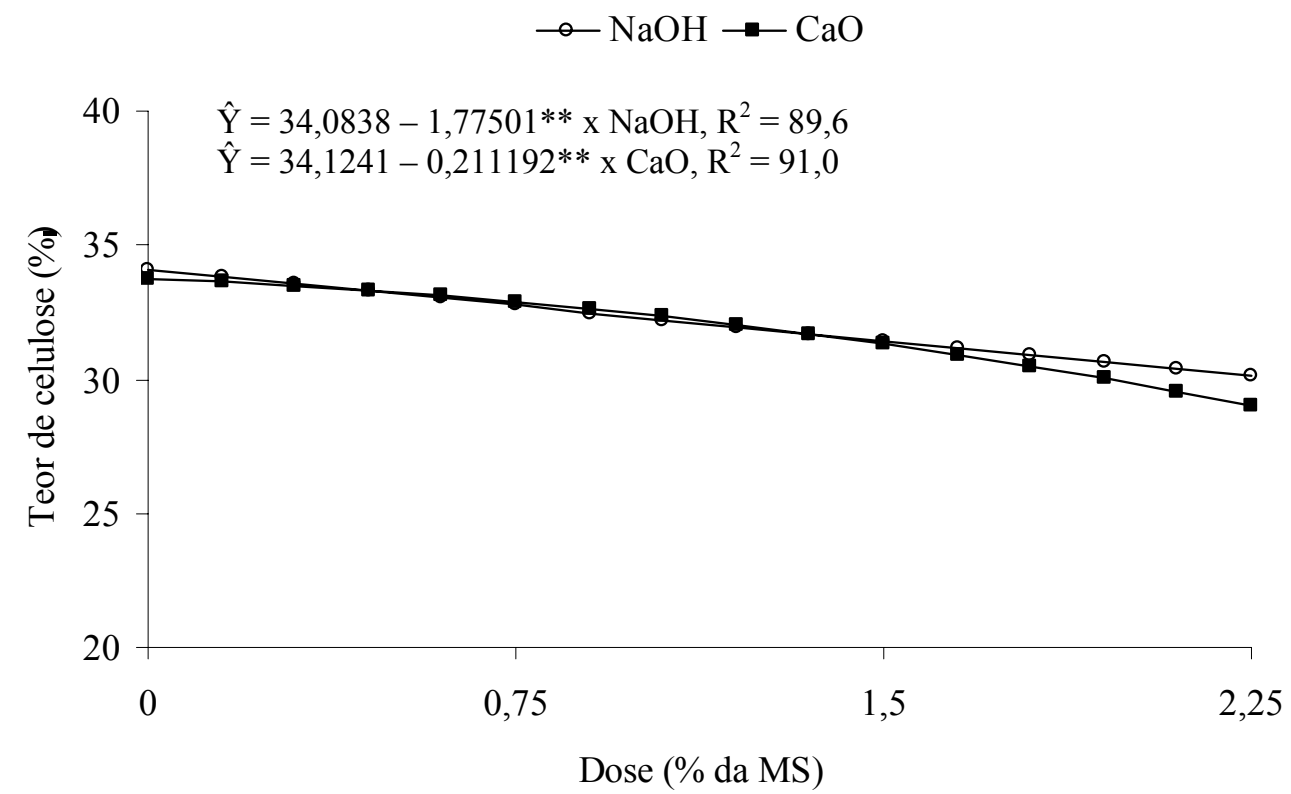

Figura 6. Teor de celulose da cana-de-açúcar tratada com diferentes doses de hidróxido de sódio $(\mathrm{NaOH})$ ou óxido de cálcio $(\mathrm{CaO})$. $* *$ Significativo a $1 \%$ de probabilidade. 
O teor médio de celulose foi de $34,1 \%$ para a cana-de-açúcar sem aditivo e de 30,2 e $29,0 \%$ para a cana hidrolisada com $2,25 \%$ de $\mathrm{NaOH}$ e $\mathrm{CaO}$, respectivamente, o que representa reduções de 12,9 e $17,6 \%$. Esse resultado está relacionado à ação degradadora dos álcalis sobre os complexos lignocelulósicos dos volumosos tratados com produtos alcalinos. Os álcalis solubilizam parte da hemicelulose, expandindo a celulose e tornando a fração fibrosa de melhor qualidade (Klopfenstein e Kraus, 1972).
A interação aditivos versus doses $(\mathrm{P}<0,05)$ influenciou o teor de lignina, que, na cana-deaçúcar tratada com $\mathrm{NaOH}$, apresentou comportamento quadrático $(\mathrm{P}<0,05)$, com valor mínimo de $0,13 \%$ no nível de $1,63 \%$ de $\mathrm{NaOH}$ (Fig. 7), enquanto, na cana-de-açúcar sem aditivo, manteve-se constante $(7,1 \%)$. Entre os aditivos, o $\mathrm{NaOH}$ foi mais eficiente em reduzir a lignina da cana-de-açúcar hidrolisada que o $\mathrm{CaO}$, e a dose de $2,25 \%$ foi a que promoveu maior redução do teor de lignina, independentemente do aditivo.

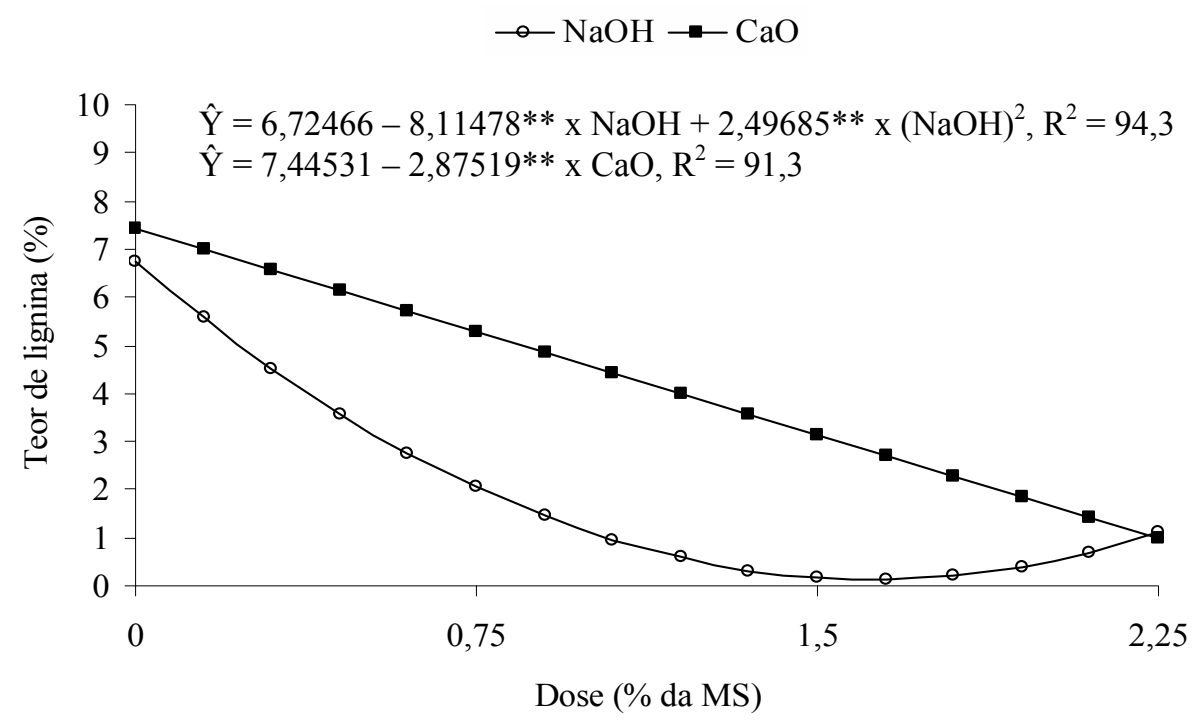

Figura 7. Teor de lignina da cana-de-açúcar tratada com diferentes doses de hidróxido de sódio $(\mathrm{NaOH})$ ou óxido de cálcio $(\mathrm{CaO})$. ${ }^{*}$ Significativo a $1 \%$ de probabilidade.

Neste estudo, houve efeito $(\mathrm{P}<0,05)$ das doses sobre o teor de matéria mineral (MM), que apresentou aumento linear conforme aumentaram as doses de $\mathrm{NaOH}$ e $\mathrm{CaO}$ (Fig. 8). A cana-deaçúcar sem aditivo apresentou, em média, 4,1\% de $\mathrm{MM}$, enquanto a cana-de-açúcar tratada com $2,25 \%$ de $\mathrm{NaOH}$ e de $\mathrm{CaO}$ apresentou, respectivamente, valores de 12,3 e $13,0 \%$, que representam aumentos de 66,7 e 68,5\%.

Entre os aditivos, o $\mathrm{CaO}$ foi o que promoveu maior aumento no teor de matéria mineral da cana-de-açúcar, em razão de sua elevada concentração de cálcio (72\%) em comparação ao $\mathrm{NaOH}$, cuja concentração é de $58 \%$ de sódio. Neste sentido, em um eventual sistema de alimentação, no qual se pretende utilizar a canade-açúcar hidrolisada como volumoso, é imprescindível o balanceamento de minerais na dieta total.

Pires et al. (2006) estudaram o tratamento do bagaço de cana-de-açúcar com $\mathrm{NaOH}$ e relataram que o teor de sódio no bagaço de canade-açúcar hidrolisado aumentou linearmente, $0,28 \%$ a cada unidade de $\mathrm{NaOH}$ adicionada.

As doses de $\mathrm{NaOH}$ e $\mathrm{CaO}$ provocaram aumento linear $(\mathrm{P}<0,05)$ na digestibilidade da matéria seca da cana-de-açúcar (Fig. 9), que aumentou 9,4 e $4,1 \%$, respectivamente, a cada unidade de $\mathrm{NaOH}$ e $\mathrm{CaO}$ adicionada à cana-de-açúcar. Estimados pela equação de regressão, os valores de digestibilidade obtidos com as doses de 0; 0,75; 1,5 e $2,25 \%$ de $\mathrm{NaOH}$ e de $\mathrm{CaO}$ foram de 58,6 ; 65,$7 ; 72,7$ e $79,7 \%$ e de 60,$6 ; 63,7 ; 66,8$ e $69,9 \%$, respectivamente. 


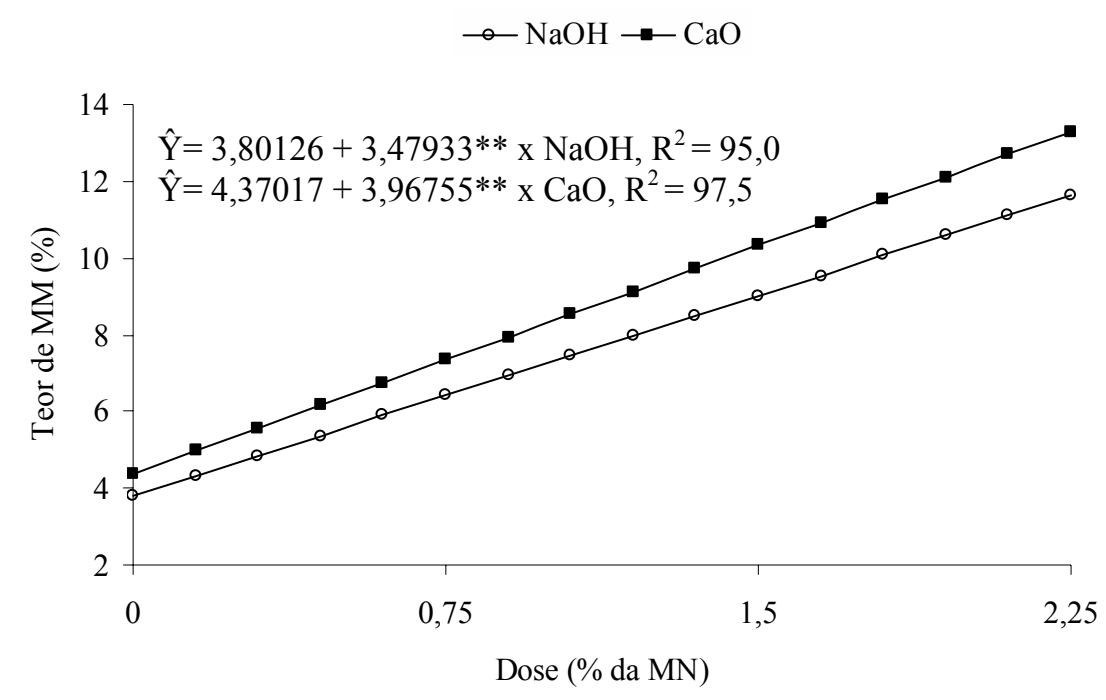

Figura 8. Teor de matéria mineral (MM) da cana-de-açúcar tratada com diferentes doses de hidróxido de sódio $(\mathrm{NaOH})$ ou óxido de cálcio $(\mathrm{CaO}) .{ }^{*}$ Significativo a $1 \%$ de probabilidade.

A maior digestibilidade da cana-de-açúcar hidrolisada pode ser atribuída às alterações químicas no material, uma vez que os componentes da parede celular diminuíram com a adição de $\mathrm{NaOH}$ e $\mathrm{CaO}$. A lignina, um composto fenólico nutricionalmente indigestível pelos microrganismos ruminais, também reduziu, o que pode ter contribuído para o aumento da digestibilidade do material tratado.
Manzano et al. (2000) encontraram valores de 32,$4 ; 48,7$ e $62,4 \%$ para a digestibilidade da matéria seca do bagaço de cana-de-açúcar sem aditivo e tratado com $2 \%$ de $\mathrm{Na}_{2} \mathrm{~S}+3 \%$ de $\mathrm{NaOH}$ e $4 \%$ de $\mathrm{Na}_{2} \mathrm{~S}+4 \%$ de $\mathrm{NaOH}$, respectivamente. Embora os autores tenham utilizado uma fonte sulfurosa associada ao $\mathrm{NaOH}$, a ação do $\mathrm{NaOH}$ foi maior sobre o bagaço e melhorou sua digestibilidade.

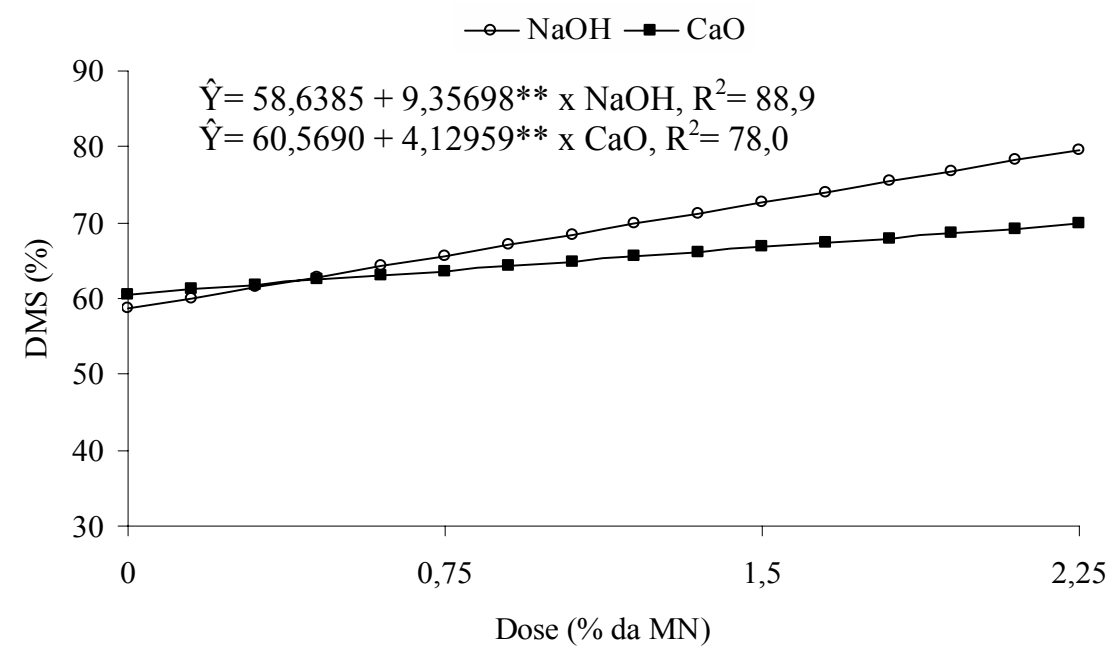

Figura 9. Digestibilidade da matéria seca (DMS) da cana-de-açúcar tratada com diferentes doses de hidróxido de sódio $(\mathrm{NaOH})$ ou óxido de cálcio $(\mathrm{CaO}) .{ }^{*}$ Significativo a $1 \%$ de probabilidade. 


\section{CONCLUSÕES}

Hidróxido de sódio e óxido de cálcio melhoram o valor nutritivo da cana-de-açúcar. O hidróxido de sódio é o mais eficiente, e tanto o hidróxido de sódio quanto o óxido de cálcio controlam a temperatura da cana-de-açúcar quando picada, hidrolisada e armazenada em temperatura ambiente.

\section{REFERÊNCIAS BIBLIOGÁFICAS}

BARBOSA, M.H.P.; SILVEIRA, L.C.I. Cana-deaçúcar: variedades, estabelecimento e manejo. In: SIMPÓSIO SOBRE MANEJO ESTRATÉGICO DA PASTAGEM, 3., 2006, Viçosa. Anais... Viçosa: UFV/DZO, 2006. p.245-276.

CÂNDIDO，M.J.D.; NEIVA，J.N.M.; PIMENTEL, J.C.M. et al. Avaliação do valor nutritivo do bagaço de cana-de-açúcar amonizado com ureia. Rev. Bras. Zootec., v.28, p.928-935, 1999.

CARVALHO, G.G.P.; PIRES, A.J.V.; VELOSO, C.M. et al. Valor nutritivo do bagaço de cana-deaçúcar amonizado com quatro doses de ureia. Pesq. Agropec. Bras., v.41, p.125-132, 2006.

CASTRO NETO, A.G.; MOLINA, L.R.: GONÇALVES, L.C. et al. Parâmetros de fermentação de silagens de cana-de-açucar submetidas a diferentes tratamentos. Arq. Bras. Med. Vet. Zootec., v.60, p.1150-1156, 2008.

CAVALI, J. Cana-de-açúcar ensilada com óxido de cálcio, capim-elefante ou inoculante bacteriano. 2006. 60f. Dissertação (Mestrado) - Universidade Federal de Viçosa, Viçosa, MG.

EZEQUIEL, J.M.B.; QUEIROZ, M.A.A.; GALATI, R.L. et al. Processamento da cana-de-açúcar: efeitos sobre a digestibilidade, o consumo e a taxa de passagem. Rev. Bras. Zootec., v.34, p.1704-1710, 2005.

GESUALDI, A.C.L.S.; SILVA, J.F.C.; VASQUES, H.M. et al. Efeito da amonização sobre a composição, retenção de nitrogênio e a conservação do bagaço e da ponta de cana-de-açúcar. Rev. Bras. Zootec., v.30, p.508-517, 2001

KLOPFENSTEIN, T.J.; KRAUS, M.J. Chemical treatment of law qualyti roughages. J. Anim Sci., v.35, p.418-422, 1972.
MANZANO, R.P.; FUKUSHIMA, R.S.; GOMES, J.D.F. et al. Digestibilidade do bagaço de cana-deaçúcar tratado com reagentes químicos e pressão de vapor. Rev. Bras. Zootec., v.29, p.1196-1204, 2000.

PIRES, A.J.V.; REIS, R.A.; CARVALHO, G.G.P. et al. Bagaço de cana tratado com hidróxido de sódio. Rev. Bras. Zootec., v.35, p.953-957, 2006.

REIS, R.A.; ANDRADE, P.; RODRIGUES, L.R.A. Palha de arroz e feno de braquiária amonizados e suplementados com energia ou proteína na alimentação de bovinos. Rev. Soc. Bras. Zootec., v.24, p.832-840, 1995.

REIS, R.A.; RODRIGUES, R.L.A.; RESENDE, K.T. et al. Avaliação de fontes amônia para o tratamento de fenos de gramíneas tropicais. 1. Constituintes da parede celular, poder tampão e atividade ureática. Rev. Bras. Zootec., v.30, p.674-681, 2001.

RIBEIRO JÚNIOR, J.I. Análises estatísticas no SAEG. Viçosa, MG: UFV, 2001. 301p.

SANTOS, J.; CASTRO, A.L.A.; PAIVA, P.C.A. et al. Efeito dos tratamentos físicos e químicos no resíduo de lixadeira do algodão. Cienc. Agrotec., v.28, p.919923, 2004.

SARMENTO, P.; GARCIA, R.; PIRES, A.J.V. et al. Tratamento do bagaço de cana-de-açúcar com ureia. Rev. Bras. Zootec., v.28, p.1203-1208, 1999.

SILVA, D.J.; QUEIROZ, A.C. Análise de alimentos: métodos químicos e biológicos. Viçosa, MG: UFV, 2005. 235p.

SOUZA, A.L.; GARCIA, R.; PEREIRA, O.G. et al. Valor nutritivo da casca de café tratada com amônia anidra. Rev. Ceres, v.26, p.669-681, 2002.

TORRES, L.B.; FERREIRA, M.A.; VÉRAS, A.S.C. et al. Níveis de bagaço de cana e ureia como substituto ao farelo de soja em dietas para bovinos leiteiros em crescimento. Rev. Bras. Zootec., v.32, p.760-767, 2003.

VILELA, H. Melaço em pó com volumosos na alimentação de éguas em reprodução. Artigos cientificos, 2007. Disponível em: $<$ http://www.agronomia.com.br/conteudo/artigos/ artigos_melaco_po_eguas_reproducao.htm/ $>$. Acesso em: 04 mai. 2007. 